\section{Commentary: Of ghosts, phantoms, and authors}

\author{
Robert M. Sade, MD
}

A ghost author is one who writes a text or makes substantial contributions to written material, such as a scientific article, but is not credited as an author. The opposite, one who is credited as an author but makes little or no contribution to the written material, has been labeled with several descriptors, such as "courtesy," "honorary," "guest," "undeserving," or "gift" authors, but perhaps a more generic yet accurately descriptive term might be "phantom" author. A phantom is "something apparent to sense but with no substantial existence; something existing in appearance only." 1 The term seems appropriate as the inverse of ghost authorship.

Most top-tier medical journals adhere to the International Committee of Medical Journal Editors (ICMJE) criteria for authorship, which includes four criteria, all of which must be met to qualify as an author, briefly:

1. Substantial contributions to the conception or design of the work;

2. Drafting the work or revising it critically;

3. Final approval of the version to be published;

4. Agreement to be accountable for all aspects of the work. In this issue of the Journal, Noruzi and coworkers ${ }^{2}$ have extended the already expansive literature on phantom authorship by focusing on cardiothoracic surgery journals. Their survey findings were similar to those of previously published analyses in other disciplines: most responders were aware of the ICMJE guidelines, $25 \%$ thought that

From the Division of Cardiothoracic Surgery, Department of Surgery, and Institute of Human Values in Health Care, Medical University of South Carolina, Charleston, SC.

Dr Sade's role in this publication was supported by the South Carolina Clinical \& Translational Research Institute, Medical University of South Carolina's Clinical and Translational Science Award Number UL1TR001450. The contents are solely the responsibility of the author and do not necessarily represent the official views of the National Center for Advancing Translational Science of the National Institutes of Health.

Disclosures: Author has nothing to disclose with regard to commercial support.

Received for publication Oct 24, 2019; revisions received Oct 24, 2019; accepted for publication Oct 24, 2019; available ahead of print Nov 14, 2019.

Address for reprints: Robert M. Sade, MD, Medical University of South Carolina, 30 Courtenay Dr, Suite 277, MSC 295, Charleston, SC, 29425 (E-mail: sader@musc. edu).

J Thorac Cardiovasc Surg 2021;161:166-7

$0022-5223 / \$ 36.00$

Copyright $($ c 2019 by The American Association for Thoracic Surgery

https://doi.org/10.1016/j.jtcvs.2019.10.137

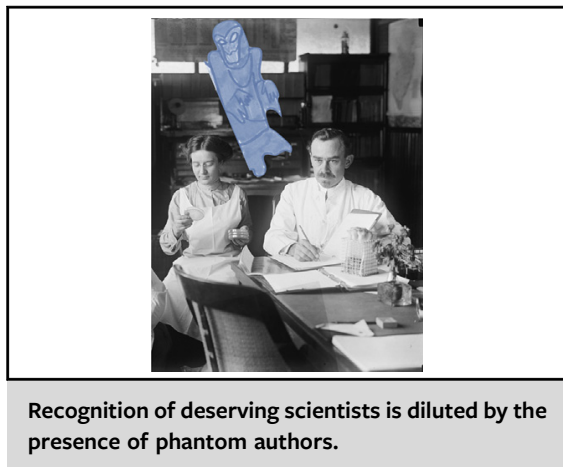

CENTRAL MESSAGE

Phantom authorship harms the scientific enterprise. Its damaging effects arise from the fact that it is fundamentally dishonest.

the article contained at least 1 honorary author, whereas $63 \%$ of articles had at least 1 author who did not meet any of the four criteria. The discordance between recognition of honorary authorship and actual failure to meet authorship criteria is a common finding in the broad literature that addresses this issue.

Several limitations of the current survey are adequately addressed by Noruzi and coworkers ${ }^{2}$ : low response rate, contact with only 1 author of each article, the probability of recall bias, and peer pressure and career risks for junior investigators. Unwarranted torturing of statistical data might be present as well, but the basic points of the article seem well justified.

Noruzi and coworkers' important contribution ${ }^{2}$ calls attention to the widespread presence of phantom authorship, but it fails to address a critical question. Why should we care about this? One might argue that another author or two does not undermine the validity of the data or the reliability of the scientific literature, so neither science nor patients are harmed. To the contrary, fake authorship is dishonest, and this dishonesty plays out in several harmful ways. Undeserved authorship pads one's bibliography and provides unjustified advantage relative to more honest colleagues in the competitions for promotion, recognition, and reputation. In some cases, adding a well-known and respected name to the list of authors is an attempt to game the peer-review system by increasing the likelihood of a positive review and consequent publication. Moreover, phantom authors know very little about 
the content of the work for which they must take responsibility, so they may gain unwarranted praise for a highquality paper and also will not be in a position to adequately defend against a serious allegation of flawed work. More generally, common understanding that undeserved authorship is widespread undermines overall confidence in the meaning and significance of scientific authorship for those who actually do the work and deserve the credit.
Dishonesty at any level of the scientific enterprise damages everyone. Phantom authorship is not harmless and should be strenuously resisted and condemned.

\section{References}

1. Merriam-Webster's Collegiate Dictionary. 11th ed. Springfield (MA): MerriamWebster; 2008.

2. Noruzi A, Takkenberg JJM, Kayapa B, Verhemel A, Gadjradj PS. Honorary authorship in cardiothoracic surgery. J Thorac Cardiovasc Surg. 2021;161: 156-62.e1. 